\title{
In vitro antineurodegenerative activity and in silico predictions of blood-brain barrier penetration of Helichrysum plicatum flower extract
}

\author{
Miloš Jovanović ${ }^{1}$, Zorica Drinici ${ }^{1 *}$, Dubravka Bigović ${ }^{1}$, Ana Alimpić Aradski², Sonja \\ DULETIĆ-LAUŠEVIĆ ${ }^{2}$, AND KATARINA Š́AVIKIN ${ }^{1}$ \\ ${ }^{1}$ Institute for Medicinal Plants Research „Dr. Josif Pančić“, Tadeuša Košćuška 1, 11000 Belgrade, Serbia \\ 2 University of Belgrade, Faculty of Biology, Institute of Botany and Botanical Garden "Jevremovac", Takovska 43, 11000 Belgrade, Serbia \\ *Corresponding author:zdrinic@mocbilja.rs
}

Received: November 3, 2020

Accepted: December 16, 2020

Published on-line: December 21, 2020

Published: December 25, 2020

\begin{abstract}
This study aimed to assess the antineurodegenerative and antioxidant activity of Helichrysum plicatum flower extract, as well as to identify extract ingredients with acceptable pharmacokinetic parameters such as gastrointestinal absorption, blood-brain barrier permeation, and P-glycoproteinmediated effusion for optimal therapeutic brain exposure. Antioxidant activity was evaluated by ABTS, FRAP, and $\beta$-carotene bleaching assays, while antineurodegenerative activity was tested using acetylcholinesterase (AChE) and tyrosinase (TYR) inhibitory activity assays. In the ABTS test, the dry extract at the highest applied concentration $(500 \mu \mathrm{g} / \mathrm{mL})$ showed better or similar antioxidant activity compared to the standards. In the $\beta$-carotene assay, all applied concentrations of the extract showed significantly higher activity than vitamin $C$. No concentration-dependent activity was observed in the AChE assay, while in the TYR assay the lowest extract concentration $(100 \mu \mathrm{g} / \mathrm{mL})$ showed the highest percentage of inhibition (27.92\%). Pharmacokinetic parameters of compounds were predicted by in silico SwissADME online tool in accordance by the rules of drug-likeness. According to the pharmacokinetic properties, we concluded that pentoxymethoxylated flavones may represent CNS drug candidates for further studies.
\end{abstract}

Key words: antioxidant, neuroprotective, tyrosinase, acetylcholinesterase, in silico

http://dx.doi.org/10.5937/leksir2040045」

\section{INTRODUCTION}

Neurodegenerative disorders such as Alzheimer's and Parkinson's disease have become a significant health problem in modern society. Their increased prevalence is associated with an increase in the life expectancy of the population (Pandey et al., 2020). In complex pathogenesis, persistent oxidative damage is recognized as one of the key factors of neuronal degeneration during aging (Vila, 2019). Namely, due to intensive metabolism, neurons are prone to increased production of highly reactive free radicals. Increased exposure to free radicals and oxidative denaturation of essential biomolecules (membrane lipids, proteins, enzymes, DNA) has led to disease progression (Ritter et al., 2020). The aging-related neuron loss in Parkinson's disease correlates directly with the accumulation of neuromelanin which is produced by tyrosinase (TYR) activity or spontaneous non-enzymatic autoxidation of dopamine (Vila, 2019). Decreased cholinergic transmission due to increased acetylcholine degradation by acetylcholinesterase (AChE) exists in various neurodegenerative diseases and is associated with memory loss in Alzheimer's patients. Therefore, both processes (oxidative damage and enhanced enzyme activity) may represent a potential target for novel antineurodegenerative therapy. Individual compounds have achieved modest symptomatic efficacy, with no causal action and poor safety that limit their chronic use (Ritter et al., 2020).

The traditional pharmacological approach of "one target - one disease" that addresses only a single target has evolved into the concept of "multitarget drug" (polypharmacology) with the idea that one drug modulates multiple targets simultaneously. In this context, plant extracts as a cocktail of pharmacologically active ingredients that act on multiple targets can realize better efficacy compared to highly specific compounds for individual targets (Morphy and Rankovic, 2008). Optimizing various activities and achieving acceptable distribution at the desired therapeutic target in brain tissue are major challenges in CNS multitarget drug discovery. An important limitation to drug distribution in the CNS is the existence of a blood- 
brain barrier (BBB) with its main active efflux gatekeeper, the so-called P-glycoprotein (P-gp) (Morphy and Rankovic, 2008; Ranković, 2015).

Helichrysum plicatum DC. (Asteraceae) is a herbaceous plant native to the Anatolian Peninsulas, Balkan, and Iran with a long tradition of use in the European ethnopharmacology (Bigović et al., 2017). It is traditionally used for wound healing, in the treatment of diabetes, kidney stones as a diuretic and litagogue, and in gastrointestinal and liver diseases as a stimulator of gastric secretion, cholagogue, choleretic, and hepatoprotectant (Aslan et al., 2007; Vujić et al., 2020). In recent years, this species has attracted the attention of scientists, and it has been confirmed that its extracts exhibit urolithic, nephroprotective, antihyperglycemic, antioxidant, antimicrobial, cytotoxic, and spasmolitic activity by various in vitro, in vivo, and ex vivo methods (Apaydin Yildirim et al., 2017; Aslan et al., 2007; Bayir et al., 2011; Bigović et al., 2010; 2017; 2011; Sezik et al., 2010). Flavones, flavanones, flavonols, and chalcones are probably the main contributors to the therapeutic activity of the extracts (Vujić et al., 2020).

As $H$. plicatum is a valuable source of pharmacologically interesting compounds with a wide range of activities, this study aimed to assess the neuroprotective and antioxidative potential of its flower extract. Assessment bioassays included three different antioxidant activity tests (ABTS, FRAP, and $\beta$-carotene bleaching assay), as well as assays regarding CNS enzymes (AChE and TYR) to assess the neuroprotective potential by different mechanisms of action. Moreover, the aim of the study was to perform in silico screening of compounds with acceptable pharmacokinetics (gastrointestinal absorption, blood-brain barrier permeation and P-glycoprotein-mediated effusion) for optimal brain exposure. To the best of our knowl edge, this is the first study of antineurodegenerative activity of $H$. plicatum flower extract.

\section{MATERIALS AND METHODS}

\subsection{Extract preparation}

Flowers heads of $H$. plicatum were purchased from Institute for Medicinal Plant Research "Dr. Josif Pančić", Belgrade (batch number 29470605). The plant material was comminuted before extraction (degree of comminution $710 \mu \mathrm{m}$, according to European Pharmacopoeia 6.0).

The dry extract was prepared according to the previously described procedure (Bigović et al., 2011). Briefly, extraction was performed with $50 \%$ ethanol (drug:solvent ratio $1: 5 \mathrm{w} / \mathrm{v}$ ) at room temperature by triple percolation. Evaporation of the obtained extract on $1 / 3$ of its volume was performed on a vacuum evaporator (Buchi rotavapor R-114) at $80{ }^{\circ} \mathrm{C}$ and then cooled to $8^{\circ} \mathrm{C}$. The obtained extract was re-extracted with ethylacetate. The yellow-orange dry extract was obtained after evaporation of ethylacetate at $60^{\circ} \mathrm{C}$.

In the extract prepared by this procedure, Bigović et al. (2011) quantified total phenols and three individual flavone aglycone. Content of total phenolics were $359.8 \mathrm{mg}$ of gallic acid equivalent per dry weight (DW) of plant extract, while content of naringenin, apigenin and kaempferol were $17.4,16.2$, and 3.8 $\mathrm{mg} / \mathrm{g}$ DW, respectively.

\subsection{Evaluation of antioxidant activity}

\subsubsection{ABTS assay}

Radical scavenging activity of the extract was evaluated by ABTS (2,2'-azino-bis (3-ethylbenzothiazoline-6- sulfonic acid) assay according to the Miller et al. (1993) procedure with slight modifications. The working solution was prepared 1216 hours before the experiment by dissolving $7 \mathrm{mM}$ of $\mathrm{ABTS}^{+}$ in $2.46 \mathrm{mM}$ potassium-persulfate and kept in a dark place at room temperature. The working solution of $\mathrm{ABTS}^{+}(1000 \mu \mathrm{L})$ was mixed with extract $(25 \mu \mathrm{L})$ in three different concentrations $(100,200$, and $500 \mu \mathrm{g} / \mathrm{mL})$ or positive controls of BHA, $\mathrm{BHT}$, and the ascorbic acid in two different concentrations (50 and $100 \mu \mathrm{g} / \mathrm{mL}$ ). The mixtures were incubated for 30 minutes at $30{ }^{\circ} \mathrm{C}$ and then the absorbance was measured at $734 \mathrm{~nm}$. The percentage of inhibition of $\mathrm{ABTS}^{+}$radical was calculated using the equation:

$$
\text { Inhibition of ABTS radical }(\%)=\frac{A_{c}-A_{s}}{A_{c}} \times 100 \% \text {, }
$$

where $A_{c}$ is the absorbance of the control (without test sample) and $A_{S}$ is the absorbance of the test samples at different concentrations. All analytical measurements were performed in triplicate and the results were expressed as mean \pm standard deviation.

\subsubsection{Ferric-reducing ability of plasma (FRAP) assay}

The total antioxidant capacity of the extract was evaluated by ferric-reducing ability of plasma (FRAP) assay according to the Benzie and Strain (1996) method with slight modifications. The ability of the extract to reduce ferric tripyridyltriazine (Fe(III)-TPTZ) complex to the ferrous tripyridyltriazine (Fe(II)TPTZ) at low $\mathrm{pH}$ was measured. FRAP reagent was prepared by mixing sodium acetate buffer $(300 \mathrm{mmol} / \mathrm{L}, \mathrm{pH} 3.6), 10$ $\mathrm{mmol} / \mathrm{L} \mathrm{TPTZ} \mathrm{in} 40 \mathrm{mmol} / \mathrm{L} \mathrm{HCl}$, and $\mathrm{FeCl}_{3} \times 6 \mathrm{H}_{2} \mathrm{O}$ solution $(20 \mathrm{mmol} / \mathrm{L})$ in proportion 10:1:1 $(\mathrm{v} / \mathrm{v} / \mathrm{v})$, respectively. Extract sample $(40 \mu \mathrm{L})$ dissolved in methanol $(100,200$, and $500 \mu \mathrm{g} / \mathrm{mL}$ ) were mixed with $1200 \mu \mathrm{L}$ of freshly prepared FRAP reagent and absorbance was measured after 4 minutes at $593 \mathrm{~nm}$. The calibration curve was constructed using a standard solution of $\mathrm{FeSO}_{4} \times 7 \mathrm{H}_{2} \mathrm{O}(0.2-1.6 \mathrm{mmol} / \mathrm{L})$, while as standards were used BHT, BHA, and ascorbic acid in concentrations of 50 and $100 \mu \mathrm{g} / \mathrm{mL}$. Results were expressed as $\mu \mathrm{mol}$ $\mathrm{FeSO}_{4} \times 7 \mathrm{H}_{2} \mathrm{O} / \mathrm{g}$ dry extract. All analytical measurements were performed in triplicate and the results were expressed as mean \pm standard deviation.

\subsection{3. $\beta$-carotene bleaching assay}

The capacity of $H$. plicatum flower extract to reduce oxidative degradation of $\beta$-carotene in a $\beta$-carotene / linoleic acid emulsion was evaluated according to the procedure of Dapkevicius et al. (1998) with slight modifications. The emulsion was prepared by dissolving $\beta$-carotene $(1 \mathrm{mg})$, linoleic acid $(50 \mu \mathrm{L})$, and Tween $40(400 \mathrm{mg})$ in $2 \mathrm{~mL}$ of chloroform. This was followed by evaporation of the chloroform and the addition of $200 \mathrm{~mL}$ of distilled water with vigorous stirring. Extract samples $(140 \mu \mathrm{L})$ dissolved in methanol in concentrations of 100 , 200, and $500 \mu \mathrm{g} / \mathrm{mL}$ were mixed with $1000 \mu \mathrm{L}$ of emulsion. BHA, BHT, and ascorbic acid in concentrations of 50 and 100 $\mu \mathrm{g} / \mathrm{mL}$ were used as standards. Absorbances were measured at zero time and after an incubation period of 120 minutes at $490 \mathrm{~nm}$. The antioxidant activity of the sample (expressed as a percentage of inhibition) was evaluated using the following equation:

$$
\text { Inhibition }(\%)=\frac{A_{120}-C_{120}}{C_{0}-C_{120}} \times 100 \%,
$$

where $A_{120}$ and $C_{120}$ are the absorbances measured in $t=120$ minutes for sample and control, respectively, while $C_{0}$ is the absorbance of control in $\mathrm{t}=0$ minutes. All analytical measurements were performed in triplicate and the results were expressed as mean \pm standard deviation.

\subsection{Evaluation of antineurodegenerative activities} 2.3.1. Acetylacholinesterase (AChE) inhibitory activity assay

Antineurodegenerative activity of the obtained extract was determined using the spectrophotometric AChE inhibitory 
Table 1. Antioxidant activity of Helichrysum plicatum flowers dry extract (HFE) compared with commercial preservatives

\begin{tabular}{llrrr}
\hline Sample $^{\mathrm{a}}$ & $\begin{array}{l}\text { Concentration } \\
{[\mu \mathrm{g} / \mathrm{mL}]}\end{array}$ & $\begin{array}{r}\text { ABTS }^{\mathrm{a}} \\
{[\% \text { of inhibition] }]}\end{array}$ & $\begin{array}{r}\text { FRAP } \\
{[\mu \mathrm{molFe}(\mathrm{II}) / \mathrm{g}]}\end{array}$ & $\begin{array}{r}\beta \text {-carotene } \\
{[\% \text { of inhibition] }}\end{array}$ \\
\hline HFE & 100 & $20.36 \pm 0.99 \mathrm{a}$ & $139.48 \pm 5.71 \mathrm{a}$ & $29.25 \pm 0.94 \mathrm{~b}$ \\
& 200 & $45.66 \pm 0.51 \mathrm{~d}$ & $357.41 \pm 6.59 \mathrm{c}$ & $32.08 \pm 1.89 \mathrm{~b}$ \\
& 500 & $63.84 \pm 1.03 \mathrm{f}$ & $547.95 \pm 6.93 \mathrm{f}$ & $45.60 \pm 2.23 \mathrm{c}$ \\
\hline BHA & 50 & $56.18 \pm 0.80 \mathrm{e}$ & $231.22 \pm 4.71 \mathrm{~b}$ & $50.79 \pm 2.76 \mathrm{~d}$ \\
& 100 & $64.95 \pm 0.63 \mathrm{f}$ & $572.85 \pm 5.71 \mathrm{~g}$ & $57.70 \pm 1.91 \mathrm{e}$ \\
\hline BHT & 50 & $37.47 \pm 0.67 \mathrm{c}$ & $364.05 \pm 5.62 \mathrm{c}$ & $48.74 \pm 1.79 \mathrm{~cd}$ \\
& 100 & $55.11 \pm 0.44 \mathrm{e}$ & $413.03 \pm 3.13 \mathrm{~d}$ & $56.29 \pm 1.44 \mathrm{e}$ \\
\hline \multirow{2}{*}{ Ascorbic acid } & 50 & $35.14 \pm 0.58 \mathrm{~b}$ & $427.56 \pm 5.18 \mathrm{e}$ & $1.73 \pm 1.19 \mathrm{a}$ \\
& 100 & $55.70 \pm 0.69 \mathrm{e}$ & $576.17 \pm 7.61 \mathrm{~g}$ & $2.99 \pm 2.13 \mathrm{a}$ \\
\hline
\end{tabular}

${ }^{a}$ Values with the same letter $(\mathrm{a}-\mathrm{g})$ in each column showed no statistically significant difference $(\mathrm{P}<0.05)$ according to the post-hoc Tukey test

b BHA, BHT, Ascorbic acid are commercial preservatives used as positive control

activity assay, previously described by Ellman et al. (1961). The activity of H. plicatum flower extract was measured by spectroscopic monitoring of yellow color intensity increase produced from tiocholine after reaction with 5,5'-dithiobis (2nitrobenzoic acid) (DTNB) ion. The extract was used in three different concentrations $(100,200$, and $500 \mu \mathrm{g} / \mathrm{mL})$, while alkaloid galantamine $(100 \mu \mathrm{g} / \mathrm{mL})$ was used as a standard. The mixture without AChE solution was used as blank (B), while the control $(C)$ did not contain extract. The reaction was initiated by adding $10 \mu \mathrm{L}$ of acetylthiocholine iodide after an incubation period of 15 minutes at room temperature. $\mathrm{Ab}$ sorbance was measured using a Tecan Sunrise SN microplate reader equipped with XFluor4 software at $412 \mathrm{~nm}$. The percentage of inhibition of AChE by samples was determined using the equation:

$$
\text { Inhibition of } \mathrm{AChE}(\%)=\frac{A_{C}-\left(A_{S}-A_{B}\right)}{A_{C}} \times 100 \% \text {, }
$$

where $A_{S}$ is the absorbance of the samples, while $A_{B}$ and $A_{C}$ are absorbances of blank and control solutions. All analytical measurements were performed in triplicate and the results were expressed as mean \pm standard deviation.

\subsubsection{Tyrosinase inhibitory activity assay}

Antineurodegenerative activity of the obtained extract was also determined using the spectrophotometric tyrosinase inhibitory activity assay, previously described by Masuda et al. (2005). The experiment was designed so that wells A contain $120 \mu \mathrm{L}$ of sodium buffer $(0.1 \mathrm{M}, \mathrm{pH} 7.0)$ and $40 \mu \mathrm{L}$ of 46 units/L tyrosinase in the same buffer; wells B contain only buffer; wells C contain $80 \mu \mathrm{L}$ of a buffer, $40 \mu \mathrm{L}$ of tyrosinase and $40 \mu \mathrm{L}$ of extract sample; wells D contain $120 \mu \mathrm{L}$ of buffer and $40 \mu \mathrm{L}$ of extract sample. The extract dissolved in sodium phosphate buffer containing $5 \%$ DMSO was used in three different concentrations $(100,200$, and $500 \mu \mathrm{g} / \mathrm{mL})$, while kojic acid $(100 \mu \mathrm{g} / \mathrm{mL})$ was used as a standard. The absorbance was measured at $475 \mathrm{~nm}$ after the addition of L-DOPA (40 $\mu \mathrm{L}$ ) and an incubation period of 30 minutes at room temperature, using Tecan Sunrise SN microplate reader equipped with XFluor4 software. Percentage of inhibition of tyrosinase was determined using the equation: $\begin{aligned} & \text { Inhibition of } \\ & \text { tyrosinase }(\%)\end{aligned}=\frac{(A A-A B)-(A C-A D)}{(A A-A B)} \times 100 \%$

, where $\mathrm{AA}, \mathrm{AB}, \mathrm{AC}$ and $\mathrm{AD}$ are absorbances of the mixtures that contained buffer and enzyme; only buffer; buffer, enzyme and sample; buffer and sample, respectively.

All analytical measurements were performed in triplicate and the results were expressed as mean \pm standard deviation.

\subsection{In silico predicting of physicochemical and pharma- cokinetic parameters by SwissADME}

Physicochemical and pharmacokinetic properties of the compounds as potential drug candidates were screened using the computer online tool SwissADME (http://www.swiss.adme.ch/). Nineteen compounds from the group of flavonoids (chalcones, flavonols, flavanones, flavones) were analyzed. Detailed chemical analysis (Vujić et al., 2020) has shown that these compounds predominate in ethanol extract of $H$. plicatum flowers and are probably the main contributor to the therapeutic activity of the extract. Canonical SMILE of compounds from the PubChem database was entered into the SwissADME software. Pharmacokinetic parameters such as gastrointestinal (GI) absorption, bloodbrain barrier (BBB) permeation, and P-glycoprotein-mediated (P-gp) effusion were predicted by software according to the rules of drug-likeness with physicochemical characteristics of successful CNS drugs candidates (Daina et al., 2017).

\subsection{Statistical analysis}

All results were reported as the mean \pm standard deviation for three replicates in each set of experiments. All the statistical analyses were performed using the SPSS software package (trial version, Dublin, Ireland). Statistical analyses were based on one-way ANOVA and post-hoc Tukey tests. The level of statistical significance is a P-value less than 0.05 .

\section{RESULTS AND DISCUSSION}

\subsection{Evaluation of antioxidant activity}

The results of antioxidant activity of different concentrations of H. plicatum flower extract (HFE) and standards investigated 
Table 2. Antineurodegenerative activity of Helichrysum plicatum flowers dry extract (HFE) compared with commercial preservatives

\begin{tabular}{llrr}
\hline Sample & $\begin{array}{l}\text { Conc. } \\
{[\mu \mathrm{g} / \mathrm{mL}]}\end{array}$ & $\begin{array}{r}\text { AChE } \\
{[\% \text { of inhib. }]}\end{array}$ & $\begin{array}{r}\text { TYR } \\
{[\% \text { of inhib. }]}\end{array}$ \\
\hline HFE & 100 & $39.53 \pm 2.12 \mathrm{a}$ & $27.92 \pm 2.74 \mathrm{~b}$ \\
& 200 & $40.99 \pm 3.42 \mathrm{a}$ & $16.45 \pm 1.21 \mathrm{a}$ \\
& 500 & $41.15 \pm 1.68 \mathrm{a}$ & $19.24 \pm 2.26 \mathrm{a}$ \\
\hline GAL & 100 & $57.11 \pm 1.68 \mathrm{~b}$ & - \\
\hline Kojic acid & 100 & - & $51.81 \pm 2.55 \mathrm{c}$
\end{tabular}

a Values with the same letter (a-c) in each column showed no statistically significant difference $(\mathrm{P}<0.05)$ according to the post-hoc Tukey test

b GAL - Galanthamine

in three different in vitro assays are shown in Table 1 . The use of complementary in vitro assays provides better predictability of antioxidant activity in real biological systems. This set of assays was chosen because they enable the assessment of antioxidant activity by various mechanisms: the electron or radical scavenging ability (ABTS and FRAP) and the lipid peroxidation prevention ability ( $\beta$-carotene bleaching assay). Also, the assays enable to assess the antioxidant activity of the extract ingredients in different reaction media: in the aqueous and lipid phase, only in the aqueous phase and at the two phases boundary (emulsion) using of ABTS, FRAP, and $\beta$ carotene bleaching assay, respectively (Moon and Shibamoto, 2009).

Concentration-dependent antioxidant activity was noticed in all assays, and the highest tested extract concentration (500 $\mu \mathrm{g} / \mathrm{mL}$ ) showed the strongest antioxidant activity. According to the results of the ABTS assay, the HFE at the highest applied concentration showed better or similar antioxidant activity compared to BHA, BHT, and vitamin $\mathrm{C}$ at both used concentrations (Table 1 ). The results of previously published study (Acet et al., 2020) indicate that the ethanol, methanol, and ethylacetate extracts of the aerial parts of $H$. plicatum (with $50 \%$ inhibition concentrations of $51.4,64.2$, and $25.9 \mu \mathrm{g} / \mathrm{mL}$, respectively) showed better ABTS radical scavenging activity compared to our extract. Ferric reducing antioxidant power of extract of $500 \mu \mathrm{g} / \mathrm{mL}$ was statistically significantly higher than standards, except BHA and vitamin $\mathrm{C}$ at a concentration of $100 \mu \mathrm{g} / \mathrm{mL}$ where it was slightly lower.

In the $\beta$-carotene test, the extract applied in concentration of $500 \mu \mathrm{g} / \mathrm{mL}$ was significantly more active than the vitamin C at both applied concentrations, while it showed lower activity than BHA and BHT. This behavior in the emulsion medium indicates that the active principles of HFE, as well as lipophilic BHA and BHT, can penetrate into formed micelles and prevent lipid peroxidation of linolic acid unlike hydrophilic vitamin C. Tepe (2005) examined $\beta$-carotene bleaching activity of a methanol extract of four Helichrysum species (H. noeanum, $H$. chionophilum, H. plicatum subsp. plicatum, and H. arenarium subsp. aucheri) obtained using Soxhlet apparatus. They reported higher activity of all tested extracts, including H. plicatum, with an inhibition rate greater than $50 \%$. This can be explained by the higher concentration of extracts they used $(2000 \mu \mathrm{g} / \mathrm{mL})$ and the different extraction procedures.

Identified antioxidant activity of the extract could be explained by the relatively high content of total phenolics which are well known highly effective natural antioxidants. In the aforementioned paper, Bigović et al. (2011) showed a close correlation between total phenolic content and radical scavenging activity examined by the DPPH method.

\subsection{Evaluation of antineurodegenerative activities}

Extract of $H$. plicatum was tested for antineurodegenerative activity at three different concentrations $(100,200$, and 500 $\mu \mathrm{g} / \mathrm{mL}$ ), and the percentage of enzyme inhibition was compared with galantamine for AChE inhibitory activity or kojic acid for TYR inhibitory activity at a concentration of 100 $\mu \mathrm{g} / \mathrm{mL}$. The activities of the tested samples in all concentrations were lower than the standards (Table 2). The highest concentration of extract showed the strongest activity (41.15 $\%)$, but no statistically significant difference between applied concentrations of extract in AChE inhibitory activity was observed. On the other hand, the lowest concentration of the extract showed significantly better TYR inhibitory activity $(27.92 \%)$ than the remaining two concentrations.

In the aforementioned study, Acet et al. (2020) examined the AChE inhibitory activity of ethanol, methanol, and ethylacetate flower extracts of $H$. plicatum from Turkey. The strongest inhibitory activity was shown by the ethylacetate extract (17.75 $\%)$, weaker by the ethanol extract $(15.3 \%)$, while methanol extract activity was not detected, which indicates that the activity depends on the type of the used extraction solvent. In a recently published paper, Aydin (2020) proved AChE inhibitory activity of flower extract of $H$. plicatum and eight isolated components. To the best of our knowledge, this is the first report on the TYR inhibitory activity of $H$. plicatum flower extract.

The antineurodegenerative activity of the HFE could be attributed to the presence of various pharmacologically active polyphenols. Polyphenols, including naringenin, apigenin, and kaempferol as the major phytoconstituents of the HFE, are recognized as compound that may exhibit significant neuroprotective effects as inhibitors of cholinesterase activity. This potent inhibitory potential can be explained by existence of multiple hydroxyl groups in polyphenol molecules. They can bind the amino acid sequence defining the active site of the enzyme via hydrogen bond, hydrophobic, and $\pi-\pi$ interaction and thus interfere with the catalytic activity of the enzyme (Jabir et al., 2018; Athipornchai et al., 2020). Through similar in vitro studies, the antineurodegenerative activity of polyphenol-rich plant drugs has been confirmed (Zdunić et al., 2020; Šavikin et al., 2018).

\subsection{Evaluation of physicochemical and pharmacokinetic parameters by SwissADME}

Abandonment of drug candidates due to pharmacokinetic weaknesses in the later stage of drug development is relatively often, so it is desirable to perform preliminary screening at an early stage of drug research. In the absence of reliable in vitro or in vivo experimental models for estimating compound penetration through BBB, computational prediction models represent valid alternatives. The SwissADME software was used to determine the physicochemical descriptors and pharmacokinetic properties of selected compounds from H. plicatum flower extracts in accordance by the roles of drug-likeness. To predict GI absorption, this program uses Lipinski's "rule of five" (Ro5). According to this rule, a compound shows high GI absorption if the $n$-octanol/water partition coefficient $(\log P)$ is $\leq 5$, the molecular weight (MW) is $\leq 500 \mathrm{~g} / \mathrm{mol}$, the number of hydrogen bond acceptors (HBA) is $\leq 10$, the number of hydrogen bond donors (HBD) is $\leq 5$, and a number of rotatable bonds (NRB) is $\leq 10$. In addition, it was experimentally determined that the compounds should have a topological polar surface (TPSA) $\leq 140 \AA^{2}$ (Daina and Zoete, 2016). Analogously, the ability of compounds to cross BBB is predicted based on physicochemical parameters that are more stringent than the prediction of absorption. 
Table 3. Predicted physicochemical and pharmacokinetic parameters of selected phytochemical compounds from Helichrisum plicatum flower extract using SwissADME software

\begin{tabular}{|c|c|c|c|c|c|c|c|c|c|}
\hline \multirow[b]{2}{*}{ Compounds } & \multicolumn{6}{|c|}{ Physicochemical properties (criteria for BBB permeability) } & \multicolumn{3}{|c|}{ Pharmacokinetic parameters } \\
\hline & $\begin{array}{c}\log \mathrm{P}^{\mathrm{a}} \\
(0.4-6.0)\end{array}$ & $\begin{array}{r}\text { MW } \\
(\leq 450 \mathrm{~g} / \mathrm{mol})\end{array}$ & $\begin{array}{l}\text { HBA } \\
(\leq 7)\end{array}$ & $\begin{array}{l}\text { HBD } \\
(\leq 3)\end{array}$ & $\begin{array}{l}\text { NRB } \\
(\leq 8)\end{array}$ & $\begin{array}{r}\text { TPSA } \\
\left(\leq 79 \AA^{2}\right)\end{array}$ & GI absorption & BBB permeability & P-gp substrate \\
\hline \multicolumn{10}{|l|}{ Standards } \\
\hline galanthamine & 1.91 & 287.35 & 4 & 1 & 1 & 41.93 & High & Yes & Yes \\
\hline kojic acid & -0.16 & 142.11 & 4 & 2 & 1 & 70.67 & High & No & No \\
\hline \multicolumn{10}{|l|}{ Chalcones } \\
\hline isosalipurposide aglycone & 1.83 & 272.25 & 5 & 4 & 3 & 97.99 & High & No & No \\
\hline arenariumoside and tomoroside A aglycones & 2.68 & 544.51 & 10 & 8 & 6 & 195.98 & Low & No & No \\
\hline \multicolumn{10}{|l|}{ Flavonols } \\
\hline quercetin & 1.23 & 302.24 & 7 & 5 & 1 & 131.36 & High & No & No \\
\hline kaempferol & 1.58 & 286.24 & 6 & 4 & 1 & 111.13 & High & No & No \\
\hline helichrysoside & 1.11 & 610.52 & 14 & 8 & 8 & 236.81 & Low & No & No \\
\hline tiliroside & 1.52 & 594.52 & 14 & 7 & 8 & 216.58 & Low & No & No \\
\hline naringenin & 1.84 & 272.25 & 5 & 3 & 1 & 86.99 & High & No & Yes \\
\hline eriodictyol & 1.45 & 288.25 & 6 & 4 & 1 & 107.22 & High & No & Yes \\
\hline \multicolumn{10}{|l|}{ Flavones } \\
\hline apigenin & 2.11 & 270.24 & 5 & 3 & 1 & 90.90 & High & No & No \\
\hline luteolin & 1.73 & 286.24 & 6 & 4 & 1 & 111.13 & High & No & No \\
\hline 3,5,6,7,8-pentamethoxyflavone & 3.02 & 372.37 & 7 & 0 & 6 & 76.36 & High & Yes & No \\
\hline $3^{\prime}, 4^{\prime}, 5,6,7$-pentamethoxyflavone & 1.10 & 372.37 & 7 & 0 & 6 & 76.36 & High & Yes & No \\
\hline dihydroxy-dimethoxyflavone & 2.20 & 314.29 & 6 & 2 & 3 & 89.13 & High & No & No \\
\hline jaceosidin & 2.11 & 330.29 & 7 & 3 & 3 & 109.36 & High & No & No \\
\hline chrysoeriol & 2.18 & 300.26 & 6 & 3 & 2 & 100.13 & High & No & No \\
\hline 5,7-dihydroxy-3-methoxyflavone & 2.56 & 284.26 & 5 & 2 & 2 & 79.90 & High & No & No \\
\hline 5,7,4'-trihydroxy-3,6-dimethoxy-3'-prenylflavone & 3.54 & 389.41 & 7 & 3 & 5 & 109.36 & High & No & No \\
\hline 4',5,7-triethoxy-3',6-dimethoxyflavone & 4.08 & 414.45 & 7 & 0 & 9 & 76.36 & High & No & No \\
\hline
\end{tabular}


The ideal candidate for CNS drugs should have a $\log P$ from 0.4 to $6.0, \mathrm{MW} \leq 450 \mathrm{~g} / \mathrm{mol}, \mathrm{HBA} \leq 7, \mathrm{HBD} \leq 3, \mathrm{NRB} \leq 8$ and TPSA $\leq 79 \AA^{2}$ (Daina and Zoete, 2016; Ranković, 2015). Additional to the fact that BBB is a physical barrier to drug passage (tight junctions between endothelial cells defy drug penetration), it is also a biochemical barrier (P-gp pumps out xenobiotics from CNS). Therefore, the possibility of efflux of selected compounds by P-gp pump was considered. It was found that CNS drugs showed a significantly lower frequency of P-gp-mediated efflux compared to non-CNS drugs, indicating the importance of these transportersin CNS therapy (Ranković, 2015).

Most of the tested compounds showed high GI absorption (Table 3). Two chalcones and two flavonols noted at least one Lipinski's violations, so they were predicted to have low GI absorption in the human body. On the other hand, it is predicted that only two of the nineteen tested compounds will be able to penetrate the blood-brain barrier. Both compounds are from the group of pentoxymethoxylated flavones $(3,5,6,7,8$ pentamethoxyflavone and $3^{\prime}, 4^{\prime}, 5,6,7$-pentamethoxyflavone). It is interesting prediction that naringenin, apigenin and kaempferol as the three major ingredients of HFE have no ability to cross the blood-brain barrier due to the high value of TPSA, while kaempferol also shows a high value of HBD. These results are in line with the statement that the possibility of penetration cross blood-brain barrier is a key obstacle that is eliminatory for many compounds in CNS drug development (Ranković, 2015). It is also promising that these compounds did not exhibit substrate specificity for the P-gp transporter. Interestingly, according to this criterion, the mentioned compounds are better candidates than the galanthamine standard. A favorable circumstance is that most of the other compounds are not a substrate for the P-gp, which may indicate a low potential for interaction with other drugs in this pathway (Ranković, 2015). Namely, P-gp is an active efflux pump on the cytoplasmic membrane that plays a major role in protecting the CNS from xenobiotics. It shows a wide substrate specificity and is, therefore, suitable for drug-drug interaction (Daina and Zoete, 2016; Ranković, 2015).

\section{CONCLUSION}

In the present study, we examined the antioxidant and antineurodegenerative activities of Helichrysum plicatum flowers extract using in vitro models. The concentration-dependent activity was observed in all antioxidant assays. In the $\beta$-carotene assay, all tested concentrations of dry extract were significantly more potent than both concentrations of vitamin $C$ standards The dry extract showed better acetylcholinesterase (AChE) inhibitory activity compared to tyrosinase (TYR) inhibitory activity at all applied concentrations. Following confirmed activities, in silico pharmacokinetic screening of selected extract ingredients was performed to the reveal predictability of gastrointestinal absorption, blood-brain barrier permeation, and P-glycoprotein-mediated effusion. According to the pharmacokinetic parameters determined by in silico method, it was concluded that candidates for CNS drugs may be pentoxymethoxylated flavones. Further comprehensive studies in animal models are required to more accurately assess the applicability of this plant extract in treatment of neurodegenerative diseases.

\section{ACKNOWLEDGMENTS}

This work was supported by the Ministry of Education, Science and Technological Development of the Republic of Serbia, grant numbers 451-03-68/2020-14/ 200003 and 451-03-68 / 2020$14 / 200178$.

\section{REFERENCES}

Acet, T., Ozcan, K. and Zengin, G. (2020). An assessment of phenolic profiles, fatty acid compositions, and biological activities of two Helichrysum species: H. plicatum and $H$. chionophilum, Journal of Food Biochemistry 44(2): e13128.

Apaydin Yildirim, B., Kordali, S., Terim Kapakin, K. A., Yildirim, F., Aktas Senocak, E. and Altun, S. (2017). Effect of Helichrysum plicatum DC. subsp. plicatum ethanol extract on gentamicin-induced nephrotoxicity in rats, Journal of Zhejiang University-SCIENCE B 18(6): 501-511.

Aslan, M., Deliorman Orhan, D., Orhan, N., Sezik, E. and Yesilada, E. (2007). In vivo antidiabetic and antioxidant potential of Helichrysum plicatum ssp. plicatum capitulums in streptozotocin-induced-diabetic rats, Journal of Ethnopharmacology 109(1): 54-59.

Athipornchai, A., Ketpoo, P. and Saeeng, R. (2020). Acetylcholinesterase inhibitor from Tabernaemontana pandacaqui flowers, Nat. Prod. Commun. 15(3): 1-5.

Šavikin, K., Živković, J., Alimpić, A., Zdunić, G., Janković, T., Duletić Laušević, S. and Menković, N. (2018). Activity guided fractionation of pomegranate extract and its antioxidant, antidiabetic and antineurodegenerative properties, Ind Crops Prod 113: 142-149.

Aydin, T. (2020). Secondary metabolites of Helichrysum plicatum DC. subsp. plicatum flowers as strong carbonic anhydrase, cholinesterase and $\alpha$-glycosidase inhibitors, Zeitschrift für Naturforschung C 75(5): 153-159.

Bayir, Y., Halici, Z., Keles, M. S., Colak, S., Cakir, A., Kaya, Y. and Akçay, F. (2011). Helichrysum plicatum DC. subsp. plicatum extract as a preventive agent in experimentally induced urolithiasis model, Journal of Ethnopharmacology 138(2): 408-414.

Benzie, I. F. and Strain, J. (1996). The ferric reducing ability of plasma (FRAP) as a measure of "Antioxidant Power": The FRAP assay, Analytical Biochemistry 239(1): 70-76.

Bigović, D., Šavikin, K., Janković, T., Menković, N., Zdunić, G., Stanojković, T. and Djurić, Z. (2011). Antiradical and cytotoxic activity of different Helichrysum plicatum flower extracts, Natural Product Communications 6(6): 1934578X1100600.

Bigović, D., Branković, S., Kitić, D., Radenković, M., Jankovi, T., Šavikin, K. and Živanović, S. (2010). Relaxant effect of the ethanol extract of Helichrysum plicatum (Asteraceae) on isolated rat ileum contractions, Molecules 15(5): 3391-3401.

Bigović, D., Stević, T., Janković, T., Noveski, N., Radanović, D., Pljevljakusic, D. and Djuric, Z. (2017). Antimicrobial activity of Helichrysum plicatum DC, Hemijska industrija 71(4): 337342.

Daina, A., Michielin, O. and Zoete, V. (2017). SwissADME: a free web tool to evaluate pharmacokinetics, drug-likeness and medicinal chemistry friendliness of small molecules, Scientific Reports 7(1): 42717.

Daina, A. and Zoete, V. (2016). A boiled-egg to predict gastrointestinal absorption and brain penetration of small molecules, ChemMedChem 11(11): 1117-1121.

Dapkevicius, A., Venskutonis, R., van Beek, T. A. and Linssen, J. P. H. (1998). Antioxidant activity of extracts obtained by different isolation procedures from some aromatic herbs grown in Lithuania, Journal of the Science of Food and Agriculture 77(1): 140-146. 
Ellman, G. L., Courtney, K., Andres, V. and Featherstone, R. M. (1961). A new and rapid colorimetric determination of acetylcholinesterase activity, Biochemical Pharmacology 7(2): 88-95.

Jabir, N., Khan, F. and Tabrez, S. (2018). Cholinesterase targeting by polyphenols: A therapeutic approach for the treatment of Alzheimer's disease, CNS Neurosci Ther. 24(9): 753762.

Masuda, T., Yamashita, D., Takeda, Y. and Yonemori, S. (2005). Screening for tyrosinase inhibitors among extracts of seashore plants and identification of potent inhibitors from Garcinia subelliptica, Bioscience, Biotechnology, and Biochemistry 69(1): 197-201.

Miller, N. J., Rice-Evans, C., Davies, M. J., Gopinathan, V. and Milner, A. (1993). A novel method for measuring antioxidant capacity and its application to monitoring the antioxidant atatus in premature neonates, Clinical Science 84(4): 407-412.

Moon, J.-K. and Shibamoto, T. (2009). Antioxidant assays for plant and food components, Journal of Agricultural and Food Chemistry 57(5): 1655-1666.

Morphy, R. and Rankovic, Z. (2008). Multitarget Drugs, The practice of medicinal chemistry, Elsevier, pp. 449-472.

Pandey, T., Smita, S. S., Mishra, A., Sammi, S. R. and Pandey, R. (2020). Swertiamarin, a secoiridoid glycoside modulates $\mathrm{nAChR}$ and AChE activity, Experimental Gerontology 138: 111010 .

Ranković, Z. (2015). CNS drug design: balancing physicochemical properties for optimal brain exposure, Journal of Medicinal Chemistry 58(6): 2584-2608.

Ritter, J., Flower, R., Henderson, G., Loke, Y., MacEWAN, D. and Rang, H. (2020). Rang and Dale's Pharmacology, $9^{\text {th }}$ edn, Elsevier.

Sezik, M., Aslan, M., Orhan, D. D., Erdemoglu, E., Pekcan, M., Mungan, T. and Sezik, E. (2010). Improved metabolic control and hepatic oxidative biomarkers with the periconception use of Helichrysum plicatum ssp. plicatum, Journal of Obstetrics and Gynaecology 30(2): 127-131.

Tepe, B. (2005). In vitro antioxidant activities of the methanol extracts of four Helichrysum species from Turkey, Food Chemistry 90(4): 685-689.

Vila, M. (2019). Neuromelanin, aging, and neuronal vulnerability in Parkinson's disease, Movement Disorders 34(10): 14401451.

Vujić, B., Vidaković, V., Jadranin, M., Novaković, I., Trifunović, S., Tešević, V. and Mandić, B. (2020). Composition, antioxidant potential, and antimicrobial activity of Helichrysum plicatum DC. various extracts, Plants 9(3): 337.

Zdunić, G., Alimpić Aradski, A., Gođevac, D., Živković, J., Duletić Laušević, S., Krstić Milošević, D. and Šavikin, K. (2020). In vitro hypoglycemic, antioxidant and antineurodegenerative activity of chokeberry (Aronia melanocarpa) leaves, Industrial Crops and Products 148: 112328. 